\title{
Hacia una suerte estructural: una reflexión a partir del concepto de "privación de libertad colectiva" en la obra de Gerald A. Cohen
}

\author{
Andrea F. Schuster ${ }^{1}$ | Universidad de Buenos Aires
}

Revista Derechos en Acción / ISSN 2525-1678 / e-ISSN 2525-1686

Año 4/NNo 10 Verano 2018/2019 (21 diciembre a 21 marzo), 459-476

DOl: https://doi.org/10.24215/25251678e265

Resumen: Todas las categorías de la suerte que distinguen los teóricos de la llamada suerte moral comparten en alguna medida que parten del análisis del impacto de la suerte en términos individuales. No obstante, también tiene especial relevancia para el mundo jurídico la suerte en su aspecto colectivo. Aquí, partiendo del análisis del concepto de "privación de libertad colectiva" desarrollado por Gerald A. Cohen, reflexionaré acerca de la suerte como elemento que priva de libertad en su aspecto estructural, sin controvertir asumiendo la premisa liberal de la existencia de la libertad en términos individuales. Así, intentaré demostrar que, si bien la suerte puede tener o no un impacto real en términos individuales en una circunstancia en particular, tiene necesaria y simultáneamente efectos en términos colectivos; que deben ser tenidos en consideración para pensar la responsabilidad que el derecho penal atribuye.

Palabras clave: suerte-moral-estructural-liberalismo-cohen-castigo

Abstract: All categories of luck distinguished by the theorists of moral luck share the fact that they consider the impact of luck only on its individual aspect. However, luck in its collective perspective has special relevance for the legal analysis. In this article, starting from the concept of "collective deprivation of liberty" developed by Gerald A. Cohen, I will reflect about luck as a fact which deprives of liberty on its structural aspect,

\footnotetext{
Agradezco especialmente al Prof. Gustavo Beade por debatir estas ideas conmigo, por sus comentarios, sugerencias y su dedicación docente.
} 
assuming the liberal premise of the existence of liberty in individual terms. This way, I will try to demonstrate that even if luck can or cannot have a real impact in individual terms in a particular circumstance, it necessarily and simultaneously has effects on its collective aspect. This should be considered by criminal law to attribute liability.

Key words: moral-luck-structural-liberalism-cohen-punishment

\section{Introducción}

El Derecho, y considero que en particular el Derecho Penal, tiene una marcada tendencia a excluir del análisis integral de las problemáticas de atribución de responsabilidad la cuestión de la libertad de decisión sobre nuestras conductas, así como la efectiva libertad de ejercicio de tales acciones. Así, por lo general, los manuales y tratados de Derecho Penal se refieren a la "voluntad", al "control", o bien utilizan el concepto de libertad otorgándole un significado mucho más restrictivo que el que el término conlleva. Ello podría ser así por el conflicto que supone introducir conceptualizaciones más amplias al término en orden a la posibilidad de atribución de responsabilidad, o bien porque los autores/as en general y en términos filosóficamente más abarcativos comparten una noción de libertad más restringida (por ejemplo, la "libertad negativa" como la no interferencia del Estado). Asimismo, las veces que los/as teóricos/as del Derecho Penal han trabajado esta cuestión lo han hecho muchas veces considerando a la libertad sólo como bien jurídico protegido y siempre en su dimensión individual (la libertad ambulatoria de la víctima individual, la libertad de expresión, por ejemplo). ${ }^{2}$

No obstante, a lo largo de este trabajo, intentaré repensar a la libertad en términos sustancialmente más amplios como

\footnotetext{
2 Respecto del bien jurídico protegido, véase von Liszt, F., La idea de fin en el derecho penal, México DF, Ed. UNAM, 1994; Kaufmann, A., Teoría de las normas. Fundamentos de la dogmática penal moderna, Buenos Aires, Dapalma, 1977.
} 
elemento fundamental a la hora de atribuir responsabilidad moral y legal. Para ello, partiré del concepto introducido por Gerald Cohen de "privación de libertad colectiva" de modo tal que si bien sostendré la existencia de libertad (efectiva) en términos individuales, también afirmaré que la existencia de tal clase de libertad no excluye la presencia de privación de libertad en su aspecto colectivo. ${ }^{345}$ Asimismo, ello supone también trabajar sobre los condicionamientos que surgen de la propia vida colectiva que deben ser tenidos en consideración a la hora de reprochar y atribuir responsabilidad penal.

Seguidamente, analizaré cuáles son los elementos introducidos por Gerald Cohen que configuran tal presencia de privación de libertad colectiva, en particular la falta de alternativas razonables, la vida en comunidad y el sentimiento de solidaridad. En este sentido, intentaré demostrar cómo la suerte configura un elemento fundamental en la privación de libertad colectiva, que puede no manifestarse en las circunstancias concretas (es decir, en el ejercicio individual de la libertad), pero que ciertamente tiene implicancias a la hora de pensar la reprochabilidad moral de las conductas. Así, analizaré cómo la suerte es una auténtica limitación a la libertad (así entendida) y, como tal, afecta nuestros juicios morales como sociedad, sin por ello significar una limitación en términos liberales clásicos (como violación a lo que manda el artículo 19 de la Constitución Nacional, por

3 Cohen, G., A., "La estructura de la privación de la libertad del proletariado", en Por una vuelta al socialismo, o cómo el capitalismo nos hace menos libres, Buenos Aires, Siglo XXI, 2014, p. 84.

4 A los fines de este trabajo, entenderemos como privación de libertad colectiva al concepto introducido por Gerald Cohen que supone que, si bien un grupo de personas es libre individualmente, tal libertad se ve técnicamente restringida en su acción por formar parte de tal o cual otro grupo. Se trata de una privación de libertad teórica pero no física. No debe confundirse este término con el encarcelamiento masivo.

5 Es importante señalar que las ideas aquí esbozadas y retomadas de Gerald A. Cohen no configuran una parte muy representativa de su producción académica. Si bien demuestran cómo entiende Cohen al marxismo y al liberalismo, su trabajo más reconocido se vincula a la discusión entablada con John Rawls. No obstante, considero que las ideas sobre las que aquí reflexiono son especialmente valiosas. 
ejemplo). ${ }^{6}$ Por último, dedicaré algunas líneas a distinguir qué diferencia implica sostener esta existencia paralela y simultánea de libertad/ privación de libertad de la noción de culpabilidad por la vulnerabilidad.

\section{Una libertad más amplia}

La libertad ha sido siempre un tema difícil de abordar para los/as teóricos/as del Derecho Penal y su trabajo ha sido más bien encuadrado en el marco de la idea del control y la voluntad. Incluso en autores que han sido reconocidos por incorporar al análisis jurídico elementos de la realidad social, puede pensarse en una perspectiva aún más amplia, incluso considerando que alguno ha expandido el análisis del control y la voluntad al "ámbito de autodeterminación". ${ }^{7}$ En este trabajo propondré que tales elementos forman parte de libertad, especialmente en su dimensión colectiva y, por lo tanto, son restringidas (la voluntad y el control) conjuntamente con ella. ${ }^{8}$

Una de las razones por las que posiblemente los/as autores/as del derecho penal no se han abocado al trabajo sobre las implicancias de la libertad es, como ya mencioné, un concepto de libertad más restringida que la que utilizaré aquí (la libertad como no interferencia, etc). Estas posturas se han sostenido con autores con los que Cohen discutió particularmente, como Nozick en el ámbito de lo que se ha denominado libertarismo de derecha, que han realizado un abordaje de la

6 Los teóricos de la llamada "suerte moral" entienden que la suerte (más allá de las categorías que establezcan) afectan los juicios morales de la sociedad. Véase NAGEL, T., "Moral Luck" en Mortal Questions, Cambridge, Cambride University Press, 1979.

7 Zaffaroni, R. E., Alagia, A. y Slokar, A., Manual de Derecho Penal: Parte General, Buenos Aires, Ediar, 2015, pp. 514-520.

8 En lo que a este trabajo concierne, los autores que se han dedicado a analizar el problema de la suerte en el derecho penal se han referido al control absoluto y la voluntad como elementos fundantes de sus posturas sobre el rol que debe tener o no la suerte (BEADE, G. A., Suerte Moral, Castigo y Comunidad, Madrid, Marcial Pons, 2017, p. 88 y NAGel, T., "Moral...", ob. cit., p.28). 
temática sin dudas cada vez más cercano a la noción de libertad como no interferencia del Estado, especialmente en el mercado (introducido como parangón de la libertad más irrestricta). Sin embargo, en este trabajo trabajaré desde una perspectiva también liberal pero especialmente más cercana a la intención de incluir en la noción de libertad el análisis de la igualdad y las teorías de la justicia. Junto con esta segunda categoría de autores/as liberales situamos a Gerald Cohen por sus puntos en común, pero no por ello sin sus particulares críticas. No es objetivo de este trabajo analizar qué han entendido como libertad toda esta gama de autores/as; la intención será trabajará la diferencia que ha introducido Cohen en su obra que, como socialista, lo ha distanciado de las ideas liberales tradicionales (las más libertarias y las más igualitaristas también). ${ }^{10}$

Uno de los puntos (el que me interesará aquí) que sitúa las ideas de Cohen dentro de las teorías liberales, pero lo aleja sustancialmente de ellas, es su percepción del desdoblamiento de la libertad en términos individuales y en términos colectivos. En su trabajo "La estructura de la privación de la libertad en el proletariado" se apresura en sus primeras líneas a asumir que "es verdad que el trabajador es libre [...] pero si de esto se infiere que (el trabajador) no se ve obligado a vender su fuerza de trabajo, se toma como punto de partida una caracterización falsa de qué constituye verse forzado a hacer algo". ${ }^{11}$ Esto significará principalmente la disociación de los ámbitos de libertad del individuo: en su faz individual y en su faz colectiva, que con agudeza dialogarán y serán el puntapié para pensar por qué tal privación de libertad es presupuesto de la desigualdad de la

9 Nozıck, R., "Anarchy, State and Utopia", Nueva York, Basic Books, 1974, pp. 262-264.

10 Cohen ha compartido y discernido en opiniones fundamentales provenientes de su propia tradición liberal. En particular, es de especial relevancia su discusión con John Rawls sobre los principios de la justicia. Acerca de ello, véase Cohen, G. A., "¿Por qué no el socialismo?" en Por una vuelta al socialismo, o cómo el capitalismo nos hace menos libres, Buenos Aires, Siglo XXI, 2014, pp. 179-207.

11 Cohen, G., A., "La estructura de la privación de la libertad...", ob. cit. p. 74. 
clase trabajadora. Esta sutil diferencia, lo mantiene en la línea de los/as teóricos/as liberales, pero lo aleja sustancialmente de las posturas más conservadoras como la de Nozick que sostendrá que el hecho de que vender su fuerza de trabajo sea su única alternativa no supone la obligación de hacerlo. En todo caso, la pregunta radicará en cómo opera este desdoblamiento de los ámbitos de libertad y qué implicancias tiene para pensar el nivel de reproche atribuible a las personas en función de la amplitud de la libertad que se posee y que se ejerce.

La idea de la privación de libertad colectiva puede ser explicada fácilmente con un ejemplo que Cohen mismo aporta: diez personas están encerradas en una habitación con una única puerta de salida cerrada con llave. La llave se encuentra en algún espacio dentro de la habitación y, de encontrarla, sólo una de esas diez personas podrá salir de la habitación (todos tienen una capacidad relativamente similar para encontrarla). La puerta sólo podrá ser abierta una vez y, tras ello, cerrará para siempre. En este sentido, puede afirmarse que subjetivamente todos y cada uno de los diez individuos en la habitación puede tomar la llave y salir. Es decir, son libres de irse y no están obligados a permanecer en la habitación; todo ello sin importar a quién de ellos lo haga. Así "es válido afirmar respecto de cada una de las personas que no está obligada a permanecer en la habitación, aunque necesariamente al menos nueve de ellas lo harán y, en efecto, todas lo hagan". ${ }^{12}$ Lo fundamental del ejemplo de Cohen en este caso es que le permite concluir que, si los/as trabajadores/as (o los individuos encerrados, en el caso previo) están objetivamente obligados/as a vender su fuerza de trabajo (a permanecer allí dentro), lo están sin importar cuál pueda ser su situación subjetiva (que efectivamente alguno/a salga de allí o un trabajador/a ascienda socialmente).

La libertad subjetiva es así influida por la libertad colectiva. Es, entonces, una libertad condicionada. Esto ya nos permite pensar que la forma de atribución de responsabilidad legal

12 Ibid., p. 82-83. 
siempre se limita al análisis de la libertad individual sin tener en consideración la totalidad de los elementos que hacen al actuar personal. Más aún, esta forma de atribución de responsabilidad olvida incluso aquellos elementos que pueden configurar un nivel de condicionamiento tal que permita afirmar que alguien "se ve forzado a", sin importar la existencia posible pero no siempre efectiva de alternativas. ${ }^{13}$ A continuación, analizaré qué elementos constituyen, según Cohen, tal privación de libertad y, posteriormente me abocaré a la inclusión de la suerte como un elemento más de ella.

\section{A. La ausencia de alternativas razonables o aceptables}

El primer punto que establece Cohen para sustentar la existencia de la privación de la libertad en términos colectivos es la ausencia de alternativas razonables o aceptables. Como Cohen se encuentra particularmente interesado en la posibilidad de los/as trabajadores/as de salir de la opresión propia de la clase trabajadora, explica que algunos niegan que el proletariado se encuentre obligado a vender su fuerza de trabajo por la existencia de otras alternativas posibles: vivir de las asignaciones gubernamentales, mendigar, o incluso encomendarse a la buena fortuna. En este sentido, Cohen explica que "el reconocimiento de que es libre de morirse de hambre deriva su potencia sarcástica del hecho de que es libre de morirse de hambre: nadie lo amenaza con mantenerlo con vida mediante, por ejemplo, la alimentación forzada" ${ }^{14}$ Así, la falta de alternativas se trata de una verdadera falta de alternativas razonables o aceptables.

En este punto también se pone de manifiesto cuáles son aquellas diferencias en virtud de las cuales Cohen se distancia de ciertas corrientes marxistas, que sostendrán en este sentido que un/a trabajador/a que tiene la opción de ascender socialmente

\footnotetext{
13 Al respecto, Nozick sostiene que la falta de alternativas implica que una persona esté forzada a hacer algo, y sostiene que tal falta de alternativas sólo es significativa cuando es producto de acciones injustas (Nozıck, R., ob. cit., pp. 262-264).

14 Cohen, G., A., "La estructura de la privación de la libertad...", ob. cit. pp. 74-75.
} 
no está obligado a vender su fuerza de trabajo y, por ende, no es un proletario. Esta es una diferencia fundamental en el pensamiento de Cohen como liberal y marxista, porque no sólo amplía las consideraciones de la idea de libertad, entendiendo que existen -no obstante la libertad individual- condicionamientos suficientes, sino que también relativiza la postura marxista que hace ver al trabajador/a preso y sin alternativa (razonable o no) de elegir cualquier cosa a razón de su clase.

\section{B. La vida en sociedad: la libertad no se analiza aisladamente}

Uno de los elementos fundamentales del ejemplo introducido por Cohen en el caso de las personas encerradas en la habitación, es la inacción de los demás como presupuesto para que uno/a de ellos pueda ejercer efectivamente la libertad subjetiva que en teoría ya tiene. Este punto no es menor y considero que es muy relevante para analizar cómo se relaciona esta libertad en sus dimensiones individual y colectiva: la libertad de salir de la habitación puede ser ejercida a condición de que nadie más tenga intenciones de hacerlo y efectivamente nadie lo haga. No importa cuáles sean tales razones para la inacción de los/as demás prisioneros/as. La condicionalidad de la libertad, más aún cuando los/as demás verán coaccionada su libertad de salir en su totalidad cuando uno de ellos lo haga, justifica para Cohen la posibilidad de hablar de una verdadera privación de la libertad.

Una de las críticas a la tesis de Cohen es aquella que sostuvo que la coacción y la privación de libertad sólo existe por las acciones humanas (y agrega el carácter intencional de tales acciones). ${ }^{15}$ Esta postura no tiene demasiado sustento y ciertamente la tesis de Cohen está dirigida a rechazar el carácter individual incluso de los factores que limitan la libertad: la

\footnotetext{
15 Uno de los principales detractores de la idea de que sólo las acciones humanas generan verdadera coerción ha sido Harry Frankfurt. Al respecto, véase FrankFuRT, H., "Coercion and moral responsiblity", Cambridge, Cambridge University Press, 1988.
} 
privación de libertad es padecida por un grupo en tanto todos se encuentren limitados a realizar la misma acción deseada, no importa de dónde provenga tal limitación. Asimismo, nadie podrá negar que quien saque a los/as individuos de la habitación estará sin dudas liberándolos, lo que supone concluir el carácter colectivo de la liberación, por el carácter colectivo e indivisible de la privación. En efecto, Cohen va más allá y se anima a decir que "si alguien se interpone en mi camino, aunque lo haga por accidente, me priva de libertad" incluso aunque tal acción no tenga esa intención. ${ }^{16}$ Es decir: la privación de libertad es mucho más frecuente que aquello que los/as liberales tradicionales intentan establecer.

\section{C. La solidaridad de los grupos}

La cuestión que introduce Cohen respecto de la solidaridad de los grupos puede ser pensada como sub-eje del carácter condicional de tal privación de libertad. En efecto, surge como respuesta a la pregunta acerca del porqué de la inacción de los/as demás individuos. Si bien este no es un punto central en la tesis de Cohen, considero que amerita algunas valoraciones, porque de este modo comienza a tener mayor relevancia la cuestión relativa a qué grupos son los afectados por tal privación de libertad. ${ }^{17}$ Supone entonces que compartir una opresión en común permite pensar que ninguno/a de ellos/as (parte del grupo desaventajado y privado colectivamente de la libertad) se contentará con una liberación individual: el sentimiento de solidaridad que existe entre ellos/as será una limitante fundamental a la hora de pensar por qué no poseen la intención de salir individualmente de la habitación. ${ }^{18}$

Si bien este elemento no parece en principio sustancial para pensar la inacción de alguno de los individuos, creo que

\footnotetext{
16 Cohen, G., A., "La estructura de la privación de la libertad...", ob. cit. p. 89.

17 Posteriormente, analizaré cómo lo expuesto puede utilizarse para entender la opresión que recae sobre el colectivo de mujeres.
}

18 Ibid., pp. 84-85. 
hay un caso que nos ayudará a echar luz a este presupuesto y es la cuestión de la autodeterminación de los pueblos. En este caso, el carácter colectivo de la privación de la libertad, incluso sin suponer coacción directa sobre los individuos, es evidente y pone de manifiesto también en el carácter colectivo de la liberación. Así, ningún individuo que es parte de un pueblo sometido a dominación colonial, o ningún particular miembro de un pueblo que lucha por su autodeterminación se verá satisfecho con una respuesta individual, como un pasaporte que indique la nacionalidad que desea. La liberación, como también la privación, es colectiva; en gran medida por el carácter de solidaridad que comparten los miembros del pueblo como parte del mismo grupo oprimido. Ello ha permitido que en el Derecho Internacional Público se reconociera también tal pasaje de lo individual a lo colectivo, al señalar que la violación al derecho de autodeterminación de un pueblo supone la violación de los derechos fundamentales de todos/as y cada uno/a de sus miembros, conjuntamente. ${ }^{19}$

\section{Hacia una suerte estructural}

Antes de precisar cómo la suerte es un elemento fundamental en el análisis de la privación de libertad según Cohen, cabe realizar una aclaración: los/as teóricos que han trabajado la cuestión de las implicancias de la suerte han diferenciado originalmente entre suerte constitutiva, situacional (circunstancial) y en el resultado.

Como señalé en un principio, los estudios relativos a las implicancias de la suerte en el mundo jurídico han nacido en el seno de un Derecho que individualiza las conductas en la sociedad y, como tal, la cuestión de la suerte en sus dimensiones

\footnotetext{
19 Así se dispone en la Resolución 1514/XV de la Asamblea General de las Naciones Unidas. Asimismo, se les reconoce a los pueblos que luchan por su autodeterminación el derecho a hacer uso de la fuerza, como excepción a la expresa prohibición que rigen las normas imperativas del Derecho Internacional (véase González Napolitano, S. (coord..) et. al., Lecciones de Derecho Internacional Público, Buenos Aires, Erreius, 2015, p. 33.)
} 
situacional y constitutiva han quedado estrictamente vinculadas al análisis de la teoría política. En este sentido, la suerte constitutiva es aquella que determina dónde nacemos, qué clase de individuos seremos, etc.; en tanto la suerte situacional se vincula con las situaciones que nos rodean, y que habilitan o no llevar a cabo determinada acción. En cuanto a la suerte en el resultado, se trata de analizar la importancia de la culminación en las acciones que emprendemos, que son esencialmente afectadas por la suerte. ${ }^{20}$

Así, considero que en el análisis de Cohen es sustancial el elemento suerte en dos ámbitos: en primer lugar en su carácter constitutivo, que responde al porqué de encontrarse allí, en un estado de verdadera privación de libertad colectiva. Este es un detalle no menor, porque en este caso la privación de libertad es colectiva así como la suerte es colectiva. Es decir, si existen los demás elementos de la privación de la libertad colectiva (la solidaridad entre los grupos y el carácter condicionado al accionar de los demás, etc.) no es porque cada una de las personas encerradas en la habitación tenga una suerte constitutiva particular y aislada; más bien comparten su suerte constitutiva, aquella que los retiene allí y que los condiciona conjuntamente en el intento de alcanzar el mismo deseo compartido. Por otro lado, en Cohen también tiene especial relevancia la suerte situacional, puesto que en tanto la posibilidad de uno de ellos de salir esté condicionada por los demás, la oportunidad no puede estar regida sino por la fortuna que puede tener al momento de intentarlo. En definitiva, la suerte constitutiva y situacional no son sino límites a la libertad colectiva y son elementos, valga la redundancia, de la privación de libertad colectiva.

Por otro lado, la suerte en el resultado es la que se ha tomado en consideración principalmente por los/as teóricos/as del Derecho Penal. Considero que la razón principal es que mientras en el análisis de la suerte constitutiva y la suerte situacional este elemento aparece como limitante de la libertad según hemos visto, en el caso del análisis de la suerte en el resultado,

20 Beade, G. A., ob. cit., p. 23. 
la idea de "suerte" se contrapone más fácilmente a la idea de control o voluntad. No obstante, es evidente que la voluntad y el control no son sino desprendimientos en el comportamiento individual de la idea de libertad, puesto que no puede haber voluntad (relevante) de hacer algo que podemos controlar, si no somos -en mayor o menor medida- libres de hacerlo. Es decir que no hay categorías de la suerte que afecten más nuestros juicios morales que otras: es la lógica misma del derecho penal la que encuentra un problema de atribución de responsabilidad al ampliar el espectro de la libertad, que incluya (pero que no se limite) a las nociones de voluntad y control y, en consecuencia, de la suerte en todas sus dimensiones. ${ }^{21}$

Así, tanto la suerte constitutiva y situacional son, principalmente, límites a la libertad en su dimensión colectiva; en tanto la suerte en el resultado es un límite a la libertad en su dimensión individual (como control o voluntad). De este modo, podemos hablar de una verdadera suerte estructural que reúne las tres categorías mencionadas: aquella que nos retiene dentro de la habitación -según el ejemplo de Cohen- y que determinará las condiciones para nuestra liberación, así como las acciones que podemos o no ejercer dentro de ella que culminen o no en los resultados deseados. Así, la suerte estructural es la forma de entender a la suerte como límite a la libertad en todos sus aspectos, incluso el colectivo y suponiendo que, como ya hemos mencionado, la dimensión individual y la colectiva se encuentran en constante diálogo y tensión.

\section{II.A. A modo de ejemplo}

Como mencioné en un principio, Cohen se encuentra particularmente interesado en justificar por qué el proletariado se

\footnotetext{
21 Así, entre otras categorizaciones de la suerte, Villar diferencia a la "suerte social" -referida en este texto como "suerte constitutiva"- de la "suerte penal", como si sólo hubiera una categoría de la suerte relevante para el Derecho Penal. En efecto, el carácter "social" de la suerte la vuelve intrínsecamente relevante para el Derecho. Véase VILLAR, M., Suerte penal, Buenos Aires, Ediciones Didot, 2016, pp. 31-35.
} 
encuentra obligado a vender su fuerza de trabajo. Ello es así porque, como marxista y liberal, comparte tal premisa marxista (que el/la trabajador/a se encuentra forzado/a a vender su fuerza de trabajo) pero busca evitar caer en un determinismo que lo aleje sustancialmente de una perspectiva liberal que le reconoce al trabajador/a cierta posibilidad de hacer. Sin embargo, no es el único caso marcado notablemente por esta disociación de la libertad con grandes implicancias en el ámbito de la suerte.

Tomemos el caso de las mujeres: es claro que se trata de un grupo al que históricamente no le han sido reconocido los derechos y ello ha tenido implicancias particulares, por ejemplo, en el mundo académico. Pocas mujeres han logrado ser titulares de cátedra y muchas menos han llegado al decanato. No obstante, alguna lo ha logrado y ello no supone la liberación de las mujeres en general ni el reconocimiento pleno de derechos en el ámbito académico. Es decir: alguna ha podido encontrar la llave y salir de la habitación, pero ello no la libera al colectivo de mujeres que ciertamente sigue sufriendo la misma privación de libertad colectiva. Más aún: las que lo han logrado lo pudieron hacer no sólo a costa de una gran cuota de esfuerzo, sino también a razón de la suerte situacional en el intento de tomar la llave y salir de la habitación. Esta cuota de esfuerzo significativa y la necesidad de la fortuna en la situación que precisó para salir de la habitación no hubiera sido tal si la suerte constitutiva hubiera estado, digamos, "a su favor". Si bien ha podido salir de la habitación, nadie podría decir que se ha "liberado", porque su suerte constitutiva (ser mujer, pertenecer a tal colectivo) sigue limitando su libertad en términos colectivos (y si bien ha podido llegar al decanato, no implica que no sufra otras dificultades provenientes de la privación colectiva de libertad que supone pertenecer al colectivo de mujeres). Como vemos, entonces, la suerte en sus tres categorías, o en su dimensión estructural, forma parte de la privación de libertad que sufre el colectivo de mujeres y que limita la posibilidad de las mujeres de ejercer y de hacer. 


\section{Un breve comentario sobre la diferencia con la culpabilidad por la vulnerabilidad}

Cabría, llegado este punto, preguntarse qué diferencia supone para el derecho tomar en consideración la noción de libertad que propone Cohen -incluyendo su relación con la suerte-, y la idea de la culpabilidad por la vulnerabilidad. En este sentido, Zaffaroni reconoce que existe variabilidad en el ámbito de autodeterminación, en la libertad de los individuos. En efecto, considera que el ámbito de la dogmática penal en que corresponde realizar este análisis es en la culpabilidad. ${ }^{22}$ Así, señala que "esta cuestión no se vincula al concepto idealista o romántico de libre albedrío, entendido como ficción según la cual todos los humanos son igualmente libres" y que "precisamente por tener diferentes ámbitos de autodeterminación se hace necesario precisar cuál fue el que, en concreto, tuvo la persona en el momento de realizar el acto ${ }^{23}$ (el destacado me pertenece).

Asimismo, Zaffaroni considerará ciertos elementos de la realidad concreta que le permitirán concluir que existe en la sociedad cierto tipo de selectividad criminalizante basado sustancialmente en estereotipos que recaen en las clases subalternas. Así, explica que "esta selección se produce en razón de una situación de vulnerabilidad" y luego agrega que "(en esta situación) juega un importantísimo papel el estado de vulnerabilidad, pero no la agota. La peligrosidad del poder punitivo se concreta en una situación particular, o sea, que algo suele hacer la persona para alcanzar esa situación concreta de vulnerabilidad". Con ello, finalmente concluye que a nadie se le puede reprochar razonablemente su estado de vulnerabilidad,

22 Cabe señalar que no es propósito de este trabajo suponer que lo que he desarrollado configura o debería configurar un elemento para la atribución (o no) de responsabilidad penal, sino demostrar qué deja fuera de ella esta concepción del Derecho Penal. Zaffaroni analiza los elementos aquí desarrollados en el ámbito de la culpabilidad; no es mi propósito pretender una nueva causal de exclusión de la culpabilidad en términos de dogmática penal.

23 Zaffaroni, R. E., Alagia, A. y Slokar, A., ob. cit., p. 508. 
sino solo el esfuerzo personal para alcanzar la situación en que el poder punitivo se concreta ${ }^{24}$.

Es claro entonces que Zaffaroni ha ampliado su noción de libertad, reconociendo que existen elementos que la limitan notoriamente, incluyendo las desigualdades sociales que generan estados de vulnerabilidad, a razón del estereotipo que recae en las clases subalternas. No obstante, como hemos visto, para este autor la vulnerabilidad sólo se toma en consideración en el momento en que el individuo hace algo que permite que el poder punitivo se concrete, como si la reducción de la libertad del agente sólo se produjera en ese momento en que el sistema penal lo selecciona, aunque la estigmatización (que da lugar a tal criminalización) sea previa. Esto implicaría una consideración del rol de la suerte situacional como único límite a la libertad (el momento de la efectiva selección), pero no toma en consideración la privación de libertad previa y colectiva (el pertenecer a una clase social estereotipada y criminalizada a priori) así como también, por consiguiente, su suerte constitutiva.

Lo fundamental de esta comparación no es reprocharle a estos/as autores/as -que han ampliado el espectro de las consideraciones a realizar para atribuir responsabilidad- que podrían haber ido aún más allá. En definitiva, la principal cuestión es que el derecho penal ha realizado un esfuerzo para que la reprochabilidad de las conductas se ajuste más a la realidad, a veces más compleja de lo que parece pretender. La importancia de análisis como el de Cohen es que permite conservar una mirada liberal y criticar en la misma línea a un liberalismo tradicional en el que se han asentado los códigos penales modernos. Lejos de tratar de introducir un nuevo elemento al análisis de la dogmática penal que tome en consideración las propuestas de Cohen, lo que aquí hemos desarrollado nos permite realizar una crítica a los presupuestos liberales detrás de la formulación de nuestras normas penales. Esta crítica no conlleva la eliminación de la idea de las libertades individuales y el ámbito de

24 Ibid., p. 510-511. 
autodeterminación más o menos restringido que permite realizar una acción, y ser responsable por ella, sino que nos permite abrir la puerta para pensar un derecho que nos permita realizar juicios desde una perspectiva más realista.

Así, a los fines de lo aquí propuesto, el elemento suerte en su aspecto estructural cobra relevancia. Ya no sólo se trata de conocer los elementos que permiten que la vulnerabilidad se concrete (en el caso de Zaffaroni), y cuál es el grado de esfuerzo requerido (más vinculado a la suerte situacional); se trata también de reconocer los grupos oprimidos, de qué forma se encuentran privados colectivamente de la libertad, de reconocer el grupo como totalidad y no sólo como conjunto de individuos aislados (pero que no dejan de serlo). En definitiva, repensar las cuestiones que permiten (o no) el ejercicio de la libertad en su faz individual en una circunstancia en particular es, simultáneamente, repensar el mérito y la reprochabilidad de una conducta, influida por la suerte en su aspecto individual pero también -para lo que aquí nos convoca- en su dimensión colectiva.

\section{A modo de conclusión}

A lo largo de este trabajo he analizado cómo el Derecho en general, y el Derecho Penal en particular, toman en consideración el concepto de libertad y qué implicancias tiene la suerte en ella. En este sentido, he partido de un concepto de libertad en términos liberales y he ampliado las conceptualizaciones acerca de ella a partir del concepto de "privación de libertad colectiva” introducido por Gerald A. Cohen. De este modo, utilizando una consideración estrictamente liberal para el análisis de la libertad individual, he intentado demostrar por qué ella se ve limitada en términos colectivos, sin por ello resultar determinista de un modo tal que sea imposible la atribución de responsabilidad.

Posteriormente, he intentado pensar qué rol tiene la suerte en estas diversas nociones de libertad -en términos individuales 
y colectivos- concluyendo que la libertad individual es esencialmente limitada por la suerte en el resultado -en tanto se trata de la voluntad y el efectivo control del agente- y, en cuanto a la suerte situacional y constitutiva, he analizado por qué su impacto radica en la libertad en términos colectivos y, por lo tanto, su existencia configura un elemento más de la privación de libertad colectiva. Así, entendiendo que todas las nociones de libertad se ven limitadas por algún aspecto de la suerte, he podido hablar de suerte estructural como límite genérico a la libertad, que puede o no manifestarse en el aspecto subjetivo o individual, según la circunstancia.

En este sentido, lejos de intentar introducir nuevos elementos al análisis de atribución de responsabilidad en términos de dogmática penal, he intentado demostrar que la suerte constitutiva y situacional -que también afectan los juicios morales de la sociedad- no han sido tomadas en consideración por el Derecho Penal a razón del presupuesto liberal en términos tradicionales en que éste se asienta, que excluye cualquier tipo de elemento colectivo. Así, he señalado que incluso en autores/as que han introducido nociones ampliadas de libertad, sólo se ha llegado a considerar la suerte situacional, más no la suerte constitutiva.

De este modo, he intentado demostrar cómo la noción de "privación de libertad colectiva" se contrapone con el liberalismo tradicional en que se asienta nuestro ordenamiento jurídico penal, sin constituir un determinismo que imposibilite la atribución de responsabilidad. Por el contrario, esta ampliada noción de libertad nos permite tener en consideración cuestiones que ya afectan nuestros juicios morales, en gran medida a la suerte de manera estructural.

Así, quedaría preguntarse qué otras consideraciones además de la suerte son excluidas por el derecho penal en su imposibilidad de pensar una libertad que tome en consideración cualquier factor colectivo, más parecido -sin lugar a dudas- al mundo en el que vivimos. 


\section{Bibliografía}

Beade, Gustavo A., Suerte Moral, Castigo y Comunidad, Madrid, Marcial Pons, 2017.

Cohen, Gerald. A., “¿Por qué no el socialismo?” en Por una vuelta al socialismo, o cómo el capitalismo nos hace menos libres, Buenos Aires, Siglo XXI, 2014.

— "La estructura de la privación de la libertad del proletariado", en Por una vuelta al socialismo, o cómo el capitalismo nos hace menos libres, Buenos Aires, Siglo XXI, 2014.

FRANKFuRT, Harry, "Coercion and moral responsiblity", Cambridge, Cambridge University Press, 1988.

González Napolitano, Silvina (Coord..), et. al., Lecciones de Derecho Internacional Público, Buenos Aires, Erreius, 2015.

Kaufmann, Armin, Teoría de las normas. Fundamentos de la dogmática penal moderna, Buenos Aires, Dapalma, 1977

NAGel, Thomas, "Moral Luck", en Moral Questions, Cambridge, Cambride University Press, 1979.

Nozick, Robert, "Anarchy, State and Utopia", Nueva York, Basic Books, 1974.

VIllar, Mario, Suerte penal, Buenos Aires, Ediciones Didot, 2016.

von Liszt, Franz, La idea de fin en el derecho penal, México DF, Ed. UNAM, 1994.

Zaffaroni, Raúl E., Alagia, Alejando y Stokar, Alejandro, Manual de Derecho Penal: Parte General, Buenos Aires, Ediar, 2015. 